\title{
A review of vehicle system dynamics in the development of high-speed trains in China
}

\author{
Weihua Zhang $\cdot$ Jing Zeng $\cdot$ Yan li
}

Received: 15 February 2013 / Revised: 18 February 2013 / Accepted: 19 February 2013 / Published online: 13 March 2013

(C) Springer-Verlag Berlin Heidelberg 2013

\begin{abstract}
The flourishing railway industry in China comes as not only a surprise for the world but also a promoter for the development of high speed railway across the globe. In this paper, a retrospect of China's high speed railway is introduced, including its railway network plans, construction progress and operation status. A synopsis of the progress made on high speed trains is also presented from their primal stage of technology acquisition to the latter stages of innovative research and development as well as the current types of bullet trains and their uses. The breakthrough of the $500 \mathrm{~km} / \mathrm{h}$ test train developed by China is also highlighted in this letter inclusive of its design, technical indexes and fundamental testing functionalities. For China to rapidly but yet successfully develop its high speed railway industry and bullet trains, fundamental research will play as much an important role as technical innovation. Sound research on the dynamics is crucial toward the high quality performance and safety operation of high speed trains which include key factors such as vehicle design, operation and maintenance solutions, integration of the track network, and the effects of coupling systems on the dynamics performance of the train system such as airflow, pantograph-catenary and power source-current collection systems. To tackle the problems associated with the increasing of train speed, we have developed a corresponding dynamics coupled system of the track-vehicle-pantographcatenary-airflow system based on vehicle system dynamics (VSD). Comparing to traditional VSD research, in addition
\end{abstract}

W. Zhang $\cdot$ J. Zeng $\cdot$ Y. li $(\bowtie)$

State Key Laboratory of Traction Power,

Southwest Jiaotong University, Chengdu, China

e-mail: liyan_0712@163.com

W. Zhang

e-mail: tpl@swjtu.edu.cn

J. Zeng

e-mail: zeng@swjtu.edu.cn to considering the coupled system dynamics between vehicle and track, wheel and rail, fluid and solid, as well as vehicle and vehicle, the newly developed VSD also vastly increases the degrees of freedom in its calculations, enlarging the traditional VSD to a vast system dynamics (also VSD), giving VSD a new meaning. This paper elaborates the modeling and coupling relations of the track-vehicle-pantographcatenary-airflow coupled system dynamics. Focusing on high speed trains, the train parameters, track status, and effects of airflow conditions on train dynamics performance was investigated as well as the safety precautions due to limitations from track irregularity and crosswinds.

Keywords China's high-speed train .

Vehicle system dynamics - High-speed railway technology · Vast system dynamics $\cdot$ Development process

\section{Introduction}

The booming development in China's railway industry comes not only as a pleasant surprise but has also given a boost for the industry across the world. Since 2004 when China first introduced the high-speed train technology and launched an ambitious construction plan for its railway network, $9,000 \mathrm{~km}$ of lines have been completed and put into operation up until June, 2012. More than 700 high-speed trains are now in service operating 1,500 runs each day. The high-speed rail industry has become an eye catching subject in China's manufacturing industry, a part and parcel of its modern railway undertaking and a first choice in public transport.

To achieve rapid development in railway technology, several key aspects are needed, such as high national economic growth development and research progresses in industrialization technology. A unique development pattern was found to 
also play a far more important role during the process. This pattern is not only characterized by a cycle of introduction, assimilation and reinvention, but by the innovative integration of various test platforms based on a coupled dynamics theory for high-speed train system. This paper introduces the development of China's high-speed railway with a focus on its technical innovation and theoretical progress.

\section{Development planning and current situation for China's high-speed railways}

\subsection{Development history for China's high-speed railways}

China started its high-speed railway construction toward the end of the last century. The Qin-Shen passenger special line was the first of its kind running $404 \mathrm{~km}$ in length with average speeds of $200 \mathrm{~km} / \mathrm{h}$ and a maximum of $250 \mathrm{~km} / \mathrm{h}$. This line was designed and built fully by Chinese engineers giving it a milestone in Chinese railway history. The Qin-Shen line was constructed in 1999 and opened up for operation in 2003.

Railways have long served as the main arteries in China's economical development, but on the other hand, due to its low speeds and scarce network, they have also caused bottlenecks that restrain further development and public transportation. Entering into the twenty-first century, how to exploit high-speed railways and maximize its potential has gradually gained public consensus. In January 2004, authorities in charge of railway construction unveiled the Medium and long tem planning for railway networks plan; in it, the total length of passenger dedicated railway lines over speeds of $200 \mathrm{~km}$ are to reach $12,000 \mathrm{~km}$ by 2020 [1]. This same number was revised up to $18,000 \mathrm{~km}$ in 2008 [2]. The intended establishment of the large-scale construction network is comprised of "four vertical and four horizontal" high-speed passenger special lines with three inter-city rail networks covering the Yangtze River Delta, Pearl River Delta and Bohai Rim. The "four vertical and four horizontal" high-speed railway network include the following lines, as shown in Fig 1:

Four vertical lines: Beijing-Shanghai Line, BeijingWuhan-Guangzhou-Shenzhen (Hong Kong) Line, Beijing-Shenyang-Harbin (Dalian) Line and ShanghaiHangzhou-Ningbo-Fuzhou-Shenzhen Line (Southeastern coastal passenger special line).

Four horizontal lines: Qingdao-Shijiazhuang-Taiyuan Line, Xuzhou-Zhengzhou-Lanzhou Line, ShanghaiNanjing-Wuhan-Chongqing-Chengdu Line and Shanghai-Hangzhou-Nanchang-Changsha-Kunming Line.

Up until now, apart from the Qin-Shen passenger, a series of other railway lines have been successively put into service to fulfill the Plan of 2004 extending the

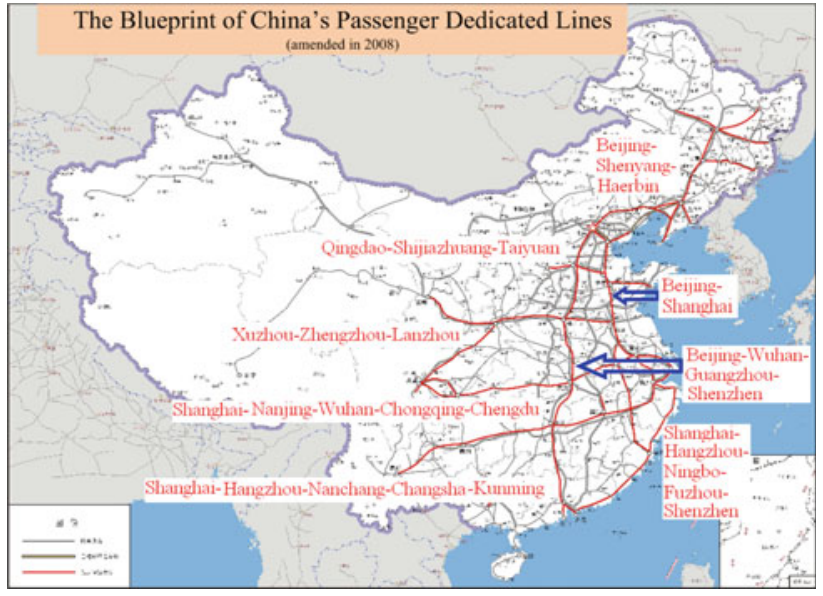

Fig. 1 Blueprint of China passenger dedicated lines

total rail length to $6,127 \mathrm{~km}$. Amongst these line, three lines were open for business in 2008, Beijing-Tianjin line, Jiaozhou-Jinan line and Hefei-Ningbo line; six lines in 2009, Shijiazhuang-Taiyuan line, Hefei-Wuhan line, DazhouChengdu line, Wenzhou-Fuzhou line, Ningbo-Wenzhou line and Wuhan-Guangzhou line; four lines in 2010, ZhengzhouXi'an line, Fuzhou-Xiamen line, Shanghai-Hangzhou line and Yichang-Wanzhou line. two lines were built in 2011, the Beijing-Shanghai line and the Guangzhou-Shenzhen section of the Guangzhou-Shenzhen-Hong Kong line.

In 2012, a total of 3,500 km of high-speed lines are expected to be open for service, including the Harbin-Dalian line, Beijing-Shijiazhuang line, Shijiazhuang-Wuhan line, Tianjin-Qinhuangdao line, Ningbo-Hangzhou line and Hangzhou-Ningbo line. Meanwhile, 1,143 km of inter-city rail lines will be ready for operation, which include lines connecting Beijing to Tianjin, Chengdu to Dujiangyan, Shanghai to Ningbo, Nanchang to Jiujiang, Guangzhou to Zhuzhou, as well as the Hainan East Ring Intercity Rail.

By the end of 2012, over 7,500 km of high-speed railway will be up for operation, making China the number one country in the world with the largest high speed rail mileage [3]. From this network grid of rails, the Beijing-Shanghai line alone covers $1,318 \mathrm{~km}$ with its bridges spanning approximately $1,140 \mathrm{~km}$ accounting for $86.5 \%$ of the entire line. The ballast-less track technology are adopted for the monolithic track bed on this line and its designed speed can reach $350 \mathrm{~km} / \mathrm{h}$. The Beijing-Shanghai line is one of the high-speed rail lines comply to the highest standard of construction in the world.

In addition to building new lines, China is also placing efforts to upgrade existing main lines and hub stations to increase their running speed and improve operating conditions. Double-track construction and electrification for the existing lines have been carried out to meet the requirement for high speed operation. By 2007, the non-operation 
length which were under repair of existing high-speed lines with running speed of over $200 \mathrm{~km} / \mathrm{h}$ reached $6,003 \mathrm{~km}$, among which the length for lines with running speed of over $250 \mathrm{~km} / \mathrm{h}$ was $846 \mathrm{~km}$. The ability of reconstructing and upgrading existing rail lines to become high speed efficient modes of transportation is becoming one of China's expertise as its refitted rail lines measure up to world standards.

\subsection{High-speed railway technologies}

\subsubsection{Railway lines}

Viaducts are set for the entire railway line with gradients generally not exceeding more than $20 \%$ and minimum curve radii of 7,000 $\mathrm{m}$. The distance between track centers lines is $5 \mathrm{~m}$.

\subsubsection{Tracks}

Ballast-less tracks with high smoothness and stability are adopted mostly for the high-speed rails in China. Since there was a lack of advanced manufacturing techniques for slab tracks in earlier days, Chinese engineers chose to first introduce a mature technique from abroad and then developed accordingly to specific conditions needed in China. In September 2004, a self-invented slab track technology was first applied on the Suining-Chongqing rail line, and a test section of $13.16 \mathrm{~km}$ with ballast-less tracks was constructed. By 2007, the whole line was completed and opened for running tests. Data of high-speed trains passing by at the speed of $232 \mathrm{~km} / \mathrm{h}$ were collected and proven to be within the required standards for design and safe operation.

In order to promote the development and application of $350 \mathrm{~km} / \mathrm{h}$ high-speed trains, China imported the ballastless track technology from German companies, including Max Bögl, RAIL.ONE, Züblin and so on. Max Bögl tracks were employed in the Beijing-Tianjin intercity line and BeijingShanghai high-speed line, the RHEDA 2000 balastless tracks were used in the Wuhan-Guangzhou passenger line, and the ones from Züblin for the Zhengzhou-Xi'an passenger line. In the Harbi-Dalian line, ballastless tracks from Japanese Shinkansen were also introduced. Engineers in China classify different tracks into several categories, such as tracks from Japanese Shinkansen are labeled as Type CRTS I, tracks from Max Bögl as slab CRTS II, tracks from Züblin as twinblock CRTS II. The new type of tracks developed by China are called CRTS III; it was first unveiled in November 2009 and then successfully applied onto the Chengdu-Dujiangyan intercity rail line.

By operating running tests and train services on approximately $100,000 \mathrm{~km}$ of lines with different track structures and types, Chinese engineers have obtained a deep understanding of the design, manufacturing, construction and maintenance technologies for various tracks, and what's more, achieved a insight of characteristics of different types of ballast-less tracks. Based on these experiences, a serialized standard system for China's high-speed railway track was developed.

In order to reduce the disturbance brought by track unsmooth on the operation of high-speed trains, high requirements are needed for track irregularities in the construction of high-speed rail lines. For example, jointless track is applied for the whole railway line. In terms for track irregularities, the manufacturing accuracy of the bearing slab of the track plate is $0.1 \mathrm{~mm}$, and the installation error is $\pm 1 \mathrm{~mm}$ in gauge, $2 \mathrm{~mm}$ in height, $2 \mathrm{~mm}$ along tracks, $2 \mathrm{~mm}$ in twist, and $1 \mathrm{~mm}$ in horizontal direction. The super-long continuous rail, $\mathrm{U} 71 \mathrm{MnK}$, is used with the rails of $60 \mathrm{~kg} / \mathrm{m}$ and $100 \mathrm{~m}$-fixed length. These rails are welded to $500 \mathrm{~m}$ in length, then laid and welded together. What's more, the large size $(1 / 38,1 / 42$, $1 / 51$, and so on) high-speed switch is applied to ensure a straight through turnout over $350 \mathrm{~km} / \mathrm{h}$ and a side through turnout $120-250 \mathrm{~km} / \mathrm{h}$.

\subsubsection{Tunnels}

The cross section area of tunnels in existing lines is generally around $64 \mathrm{~m}^{2}$. Since the cross section area has an immediate relationship with the air resistance and tightness of a train passing through, tunnels on the newly built lines are designed with a cross section area of $100 \mathrm{~m}^{2}$, with buffer structure at the entrance and with auxiliary pitches in an effort to improve aerodynamic performance.

\subsubsection{Train control system}

The advancement of Chinese high-speed railway is not just in its high-speed, but also its high density of transportation, a representative of perfect blend of high-speed and convenience of public transport. According to the specific conditions in China's railways, the CTCS series control system has been developed, among which the CTCS-2 has been applied to the $200-250 \mathrm{~km} / \mathrm{h}$ lines and the CTCS-3 for the 300 $350 \mathrm{~km} / \mathrm{h}$ lines. The CTCS-2 acts upon information transmitted by a transponder and track circuit, and CTCS-3 acts based on data transmitted via wireless. Through either of these two systems, the driver is able to operate the train with cab signals.

In light of compatibility, CTCS-3 can be run in conjunction with CTCS-2; otherwise CTCS-2 serves as a backup for CTCS-3. If a failure occurs at the Radio Block Center (RBC) or with the wireless communication, CTCS- 2 can kick in and control the train operation. Thanks to this modern control system, the minimized interval between high-speed trains can be programmed to be $3 \mathrm{~min}$, but around $5 \mathrm{~min}$ for practical and safe operation. 


\subsubsection{Traction power system}

The single-phase AC $27.5 \mathrm{kV} / 50 \mathrm{~Hz}$ power supply system is applicable for trains in China. For high-speed trains, the $2 \times 27.5 \mathrm{kV} / 50 \mathrm{~Hz}$ auto transformer (AT) system are more commonly used with distances between the substations around $50 \mathrm{~km}$. Traditionally the catenary system is suspended in a simple manner and this manner is also applied in the Beijing-Tianjin line, the first inter-city passenger line with the designed speed of $350 \mathrm{~km} / \mathrm{h}$. To improve the quality of pantograph-catenary current collection, especially to satisfy the needs for double-pantograph current collection at the speed of $350 \mathrm{~km} / \mathrm{h}$, suspension of the elastic catenary chain is adopted whose stiffness is in higher consistency with the catenary. Meanwhile, the tension of the contact wire is raised to over $30 \mathrm{kN}$.

\section{Development process of China's high-speed trains}

China' researches on the high-speed trains can be dated back to the end of last century and its first high-speed train, 'China Star', as shown in Fig. 2, domestically designed and manufactured, was developed at the beginning of the twenty-first century. 'China Star' is a set of electric motor train units using the $\mathrm{AC}$ driving system and centralized power network. The units are marshaled in the manner of 2M9T, with its full capacity of as many as 726 passengers. In November 27 , 2002, in its final test run, 'China Star' set the recorded speed of $321.5 \mathrm{~km} / \mathrm{h}$ at that time in China.

To develop high-speed trains faster and more advanced, the Chinese State Council unveiled a guideline to "Forge China-owned brand through importing advanced technology and joint design and manufacture". In accordance with this policy, the Railway Ministry launched the Project "Introduction-assimilation-reinvention". Under this program, $200 \mathrm{~km} / \mathrm{h}$ high-speed trains were introduced from Alstom, Bombardier and Kawasaki Heavy Industries (KHI)

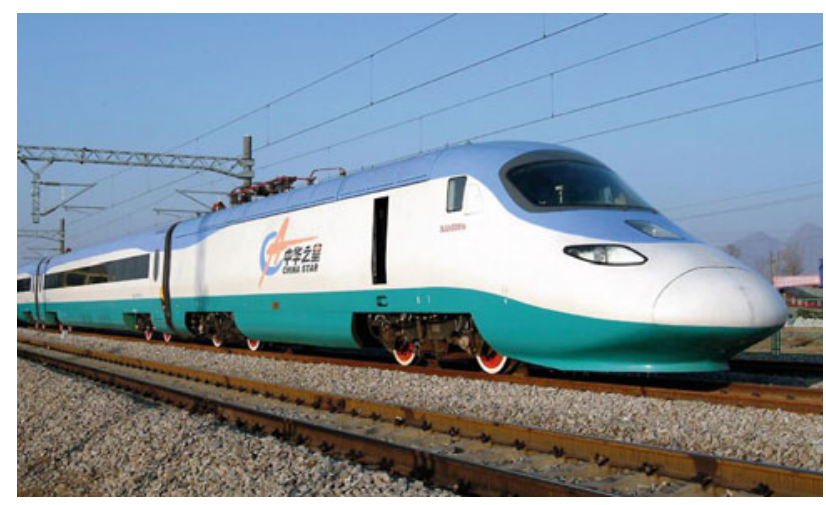

Fig. 2 'China Star' high-speed EMU in 2004, and $300 \mathrm{~km} / \mathrm{h}$ units imported from Siemens in 2006. The high-speed trains currently made and used in operation are CRH series units (China Railway High-speed). This series production include CRH1 (joint production with Bombardier), CRH2 (based on the technology from KHI), CRH3 (based on the technology from Siemens), CRH5 (based on the technology from Alstom), CRH6 and CRH380. All units in this series are in the category of high-speed distributed-power electric multiple units (EMU) and CRH6 was domestically developed and used for intercity high-speed lines.

High-speed trains need to meet the requirements of long transport distance, large traffic volume, high service density and short travel time. These demands request a better design, operation conditions and maintenance. For the nationalization of high-speed train technology, and subsequently its reinvention and self-innovation, the Railway Ministry has mobilized national resources to carry out key technology researches in this area. The key technologies for high-speed train can be generalized into the following nine categories: system integration, car body, bogie, traction transformer, traction converter, traction motor, traction transmission and control system, control network system for the train, braking system. Besides these, ten supplementary technologies in high-speed railways are decided which include the air conditioning system, dejectas collection equipment, vehicle doors, vehicle windows, vestibule diaphragm, coupler and buffer devices, pantographs, supplementary power system, internal decoration materials, seats and other related technologies.

Through the importation of advanced technology at the time followed by its digestion and assimilation, the nationalization and reinvention of high speed railways was realized. At present, the high-speed trains are classified into two categories based on speeds of 300-350 and 200-250 km/h, as well as eight production types, such as CRH1, CRH2, CHR3, CRH5, CRH6, CRH380A, CRH380B, and CRH380D (being developed jointly with Bombardier).

By the end of June 2012, there will be 705 high-speed trains (that is 908 if marshaled by a smaller group of 8 vehicles). Among these, trains of $300-350 \mathrm{~km} / \mathrm{h}$ will constitute 319 (457 marshaled by a group of 8 vehicles). On the day -to-day routes, 460 trains will service up to 1,500 runs each day.

During the 2012 Chinese New Year holiday which is by far the busiest time a year, 600 trains were put into service and completed 1,790 runs. The punctuality rate for the service was above $98 \%$. Since the opening of the Beijing-Shanghai high-speed line, its operation has been safe, stable and all under control earning it the nicknames "land flight" and "city airbus". Through its one-year operation, its load factor has increased to 56,614 trains carrying 52.6 million passengers on the line in its entirety. During peak hours, 210 trains operate on the line carrying over 200,000 passengers daily. 
Taking the CRH500 test train as an example, which was ingeniously developed by CSR Qingdao Sifang Locomotive and Rolling Stock Co. with a higher test speed. Details about its technical characteristics and parameters are provided below, and the purpose for its development is, within a wider speed range, to carry out prospective, basic and theoretical research in terms of operation safety and reliability. Such researches are mainly focused on three scientific objectives:

I. In-depth investigation of the safe operation for highspeed trains.

Safety is a crucial indicator for the train technology development. To achieve higher safety tolerances in design and better technical guidance for practical engineering and operation, the safety safeguard system needs to be explored, to ensure stable running, good structural integrity and a harmonious vehicle-track-catenary interaction while the train is running at high speed.

II. To provide a testing platform for fundamental research. Prospective, fundamental and theoretical research need to be performed based on data provided by the test runs of trains running at higher and wider speed ranges. By doing this, the dynamics behaviors, characteristics and laws of operation of high speed trains will be better understood and further industry applications and sustainable innovation can be realized.

III. To provide a testing platform for novel materials and new technology.

Through the testing of novel materials and application of new technology, researchers will help advance and optimize the high-speed train technical system, maintaining the momentum for sustainable development of China's own high seed railway industry, and perfecting the existing standard system.

The test train is developed based on the innovation achievements of the new generation high-speed train CRH380A. The guarantee of safe and reliable operation at higher speed is taken as the research goal. It focuses on how to improve the crucial speed, traction power as well as reduce drag resistance. Other aspects, such as systems integration, nose and car body, bogie, traction and braking systems are also undergoing innovative research.

Main Technical Parameters for the CRH500 high-speed train are shown in Table 1.

Technical characteristics:

- Head shape of the leading and tailing cars are designed differently: to meet the testing requirements of up to $500 \mathrm{~km} / \mathrm{h}$, the aero-dynamic resistance onto the leading car should be reduced as much as possible, as well as the aero-dynamic lift on to the tailing car. For this rea-
Table 1 Parameters for CRH500 high-speed train

\begin{tabular}{ll}
\hline Item & Parameter \\
\hline Train marshalling & 6 in one unit, all motor cars \\
Operating speed & $400 \mathrm{~km} / \mathrm{h}$ \\
Test speed on line & $\geq 500 \mathrm{~km} / \mathrm{h}$ \\
Control device & IGBT water-cooled VVVF \\
Breaking type & Regenerative braking direct \\
& electro-pneumatic brake \\
Train network & Industry Ethernet \\
Power supply system & $25 \mathrm{kV} / 50 \mathrm{~Hz}$ AC through overhead cables \\
Vehicle length & $153.5 \mathrm{~m}$ \\
Leading vehicle length & $27 / 26.5 \mathrm{~m}$ (according to various head \\
& shapes) \\
Mid-vehicle length & $25 \mathrm{~m}$ \\
Vehicle width & $2,950 \mathrm{~mm}$ \\
Vehicle height & $3,650 \mathrm{~mm}$ (new wheel, pantograph \\
Bogie distance & excluded) \\
Bogie & $17,500 \mathrm{~mm}$ \\
Bogie wheelbase & Bolsterless air spring bogie \\
Wheel diameter & $2,800 \mathrm{~mm}$ \\
Track gauge & $920 / 860 \mathrm{~mm}$ \\
Maximum axle load & $1,435 \mathrm{~mm}$ \\
Traction power & $15 \mathrm{t}$ \\
Axle power & $22,800 \mathrm{~kW}$ (during testing) \\
\hline
\end{tabular}

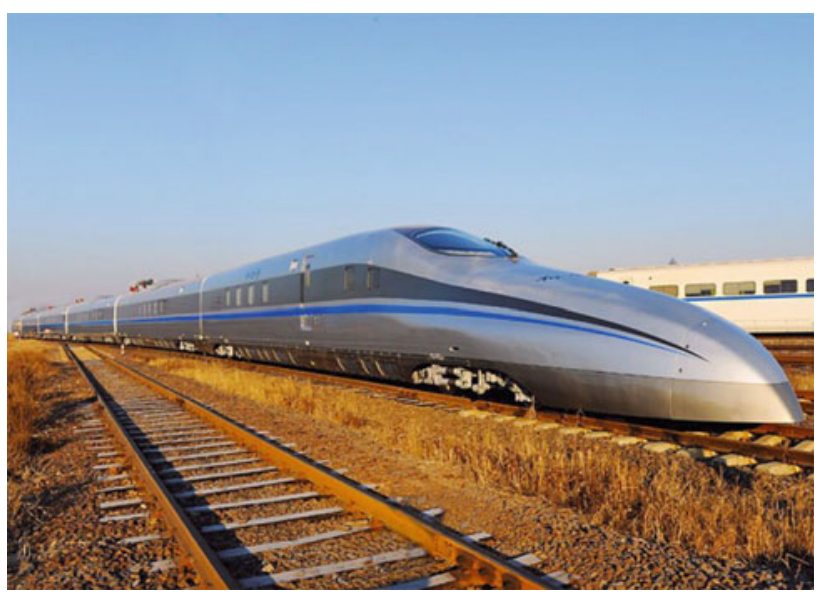

Fig. 3 Leading car of high-speed test train

son, both the leading and tailing car of the CRH500 are designed with different shapes, the leading one looks like a sword, and the tailing one like a rocket. The tailing car evolves from the leading car of CRH380A, whose shape is designed with a fine aero-dynamic performance. And the shape of the leading car is newly invented as a sword, whose structure is equipped with lower air resistance and side force. Pictures of the leading and tailing cars are shown in Figs. 3 and 4. 


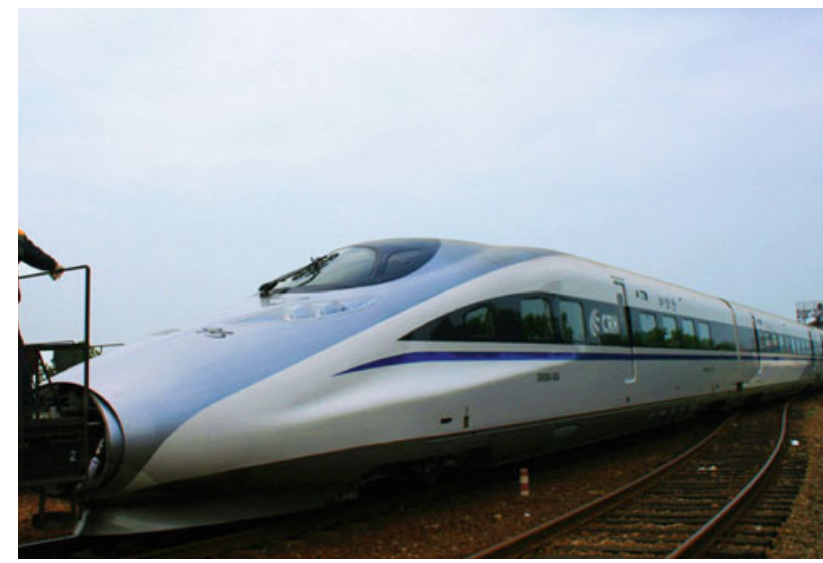

Fig. 4 Tailing car of high-speed test train

- Car body with lower aero-dynamic resistance: the structure of the car body is scaled down and optimized to reduce the air resistance and side air force. For this purpose, the car body width of CRH380A is reduced to 2,950 from $3,380 \mathrm{~mm}$. On the other hand, the car height is cut down to 3,650 from $3,700 \mathrm{~mm}$, and the train roof arc is enlarged to increase the stiffness of the car body and decreases the side air force that might exert onto it.

- Bogie with larger wheelbase: taking into account the layout of high-power motors, the wheelbase is increased to 2,800 from 2,500 $\mathrm{mm}$ in CRH380, thus the hunting critical velocity of the train can be lifted up. The bogie is bolsterless, and the anti-roll bar is added. Redundancy design is adopted for the anti-hunting dampers; flexibility of the secondary suspension is intensified. Through the above transformations, the bogie gains a higher stability and better damping effect; its critical velocity can reach $750 \mathrm{~km} / \mathrm{h}$, with enough redundancy at the test speed of $500 \mathrm{~km} / \mathrm{h}$.

- Larger traction power: to reduce the air resistance during the operation at high-speed, the traction power needs to be increased, while the car body cross sections being decreased and the head shapes for lead and tail cars optimized. With the whole train all motor cars, the axel power of $950 \mathrm{~kW}$ is the highest volume for traction motors equipped in present high-speed trains.

- Newly developed network: the test train uses the network recently developed by the Zhuzhou Electric Locomotive Research Institute, which adopts the Industry Ethernet for large information transmission during the process of operation, control and safety management. Meanwhile, a network system particularly for test and measurement is installed onboard for simultaneous collection of testing signals.

- Adoption of new materials: many new technologies and materials are adopted in the test train which include Ethernet ring network, wind drag braking, and new materials such as carbon fiber, magnesium alloy, nanometer soundproof material, and so on.

\section{Vast system dynamics for high-speed train}

For China to rapidly but yet successfully develop its highspeed railway industry and high-speed trains, fundamental research plays as much an important role as technical innovation. Sound research on the dynamics is crucial toward the high quality performance and safety operation of highspeed trains which include key factors such as vehicle design, operation and maintenance solutions, integration of the track network, and the effects of coupling systems on the dynamics performance of the train system such as airflow, pantographcatenary and power source-current collection systems.

With the increasing of speeds, the interaction between the train and the tracks, the catenary and the air flow are intensified obviously. Irregularities on tracks produce the largest disturbances for high-speed trains. The horizontal and longitudinal cross section parameters of the track play an important part in the influence on the train riding comfort and operating safety. Those parameters can be classified as parameters for track curve, transition curve, gradient, variable slope transition section Among all these influential factors, track irregularity, particularly the track twist caused by track settlement, have a direct effect on train operation conditions. Besides these factors, other track intangibles such as track stiffness, rail surface conditions (adhesion coefficients) will also affect the dynamics performance of a high-speed train.

In high-speed trains, air flow will not only exert aeroresistance on the vehicle itself, but also disturb its operation performance, and even jeopardize the running safety when situations become out of control. The vibration of the pantograph and catenary will no longer be self-excited, but act under the influence of the dynamic characteristics of the pantograph-catenary system. Their motion gets affected by the vibration of car roof and the air flows disturbing around the car body. Sometimes the pantograph or catenary lose contact when the influence becomes large enough. In light of the above reasons, the dynamics of high-speed train is not only decided by the dynamics characteristics of the train itself (the pantograph included), but also affected by disturbances of the track, airflow and catenary system.

To tackle the problems associated with the increased speed, we have developed a corresponding dynamics coupled system of the track-vehicle-pantograph-catenary-airflow system based on vehicle system dynamics (VSD), which was proposed by the author in a 2006 publication [4]. Compared to traditional VSD research, in addition to considering the coupled system dynamics between vehicle and track, wheel and rail, fluid and solid, as well as vehicle and vehicle, the newly developed VSD also evolves from the 
Fig. 5 Coupled system for high-speed train

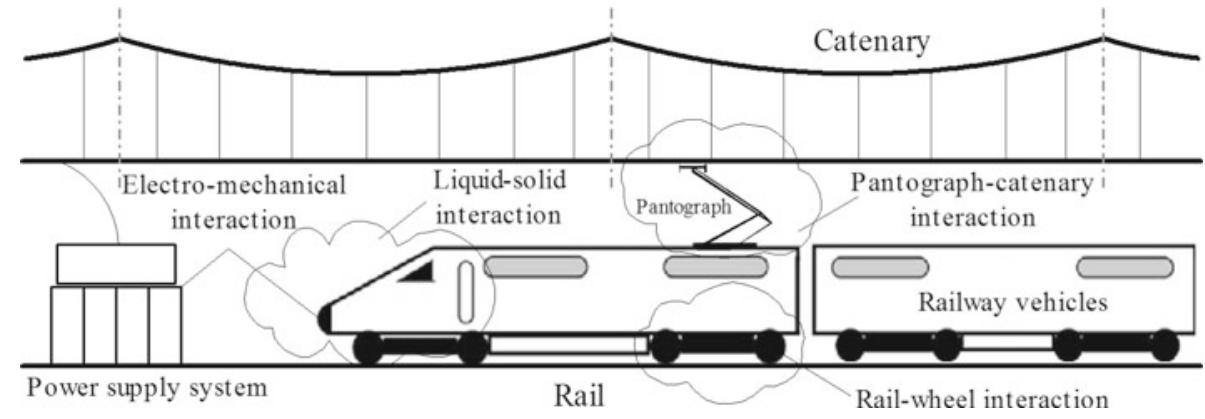

multi-rigid-body model to a rigid-flexible-fluid-body coupled model. Taking into account the complicate conditions of track, airflow and flexible body, it vastly increases the degrees of freedom in calculation, thus enlarging the traditional VSD to a vast system dynamics (also VSD), and giving VSD a new meaning.

The coupled system of the track-vehicle-pantographcatenary-airflow-electromechanic system based on vehicle system dynamics is shown in Fig. 5. The system encompasses various factors which would exert a direct influence on the train operation behaviors and its dynamics performance, such as track, pantograph and catenary, air flow, power, and signal system. The systematic modeling for separate factors, i.e., vehicle, track, pantograph-catenary, and airflow, was carried out, and then a coupled system based on the interaction and restraints between the subsystems was established [5].

Figure 6 shows the system diagram for the calculation model of the coupled system of the track-vehiclepantograph-catenary-airflow-electromechanic system based on the vehicle system dynamics model. Taking a train as a whole, the dynamics models for various vehicles should be set up first, and then the model for the entire train based on the vehicle-vehicle interaction. Due to the fact that the train consists of motor cars and trailers, which are with the same freedom of motion, dynamics model and parameters, the cyclic variable method is used. Taking the models of locomotive and trailer as basic variables, the established models are put into cyclic use and extended to the whole train, saving much computing time [6]. The dynamics model for the CRH500 can be described as:

$$
\begin{aligned}
{\left[M_{i}\right] } & \left\{\ddot{X}_{i}\right\}+\left[C_{i}\right]\left\{\dot{X}_{i}\right\}+\left[K_{i}\right]\left\{X_{i}\right\} \\
& =\left\{F_{o i}\right\}+\left\{F_{i-1 \rightarrow i}+F_{i \leftarrow i+1}\right\}
\end{aligned}
$$

Where $\left[M_{i}\right],\left[C_{i}\right]$ and $\left[K_{i}\right]$ indicate respectively the mass, damping and stiffness matrices of the Vehicle $i,\left\{F_{o i}\right\}$ is the external force on the Vehicle $i,\left\{F_{i-1 \rightarrow i}\right\}$ and $\left\{F_{i \leftarrow i+1}\right\}$ denote the interaction forces from the neighboring vehicles standing next to Vehicle $i$ at both sides (for head or trail vehicle, the interaction force only comes from one side).

For the vehicle model based on the traditional vehicle system dynamics, it is generally described as a multi-rigidbody model. However, because the car body tends to become lighter and the external disturbance frequency become higher due to an increased speed, the structural vibration of the wheelset, bogie frame, car body and other parts can not be ignored [7-11]. In recent studies, the researchers considered the car body, wheelset and frame as a flexible body. This approach however, increases the computing time drastically since the degrees of freedom are increased. Hence,
Fig. 6 Dynamics model for coupled system of high-speed train

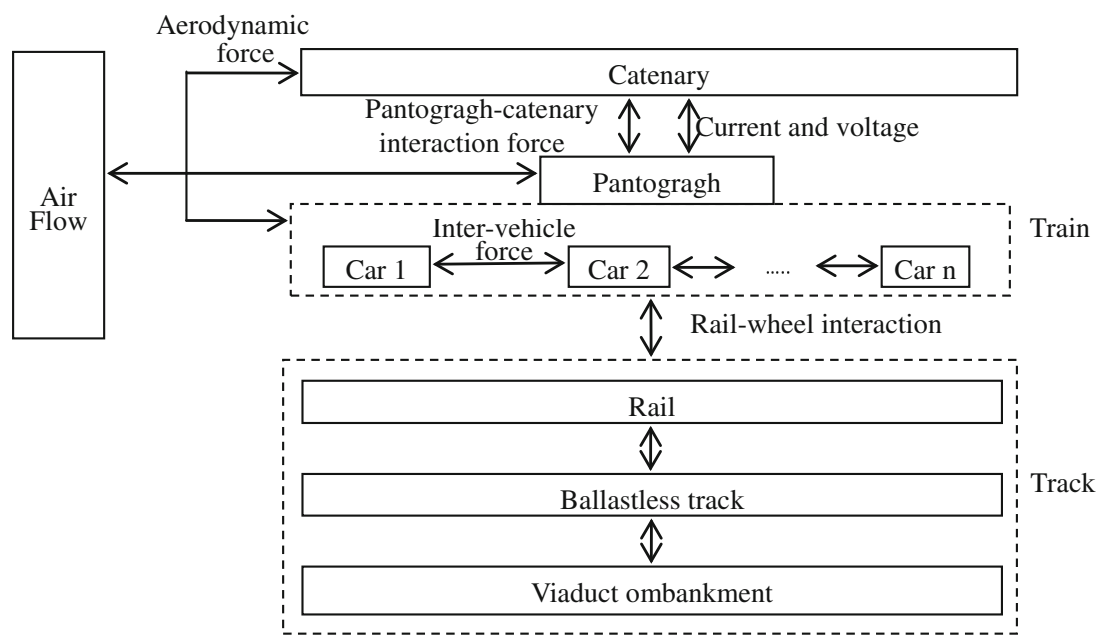




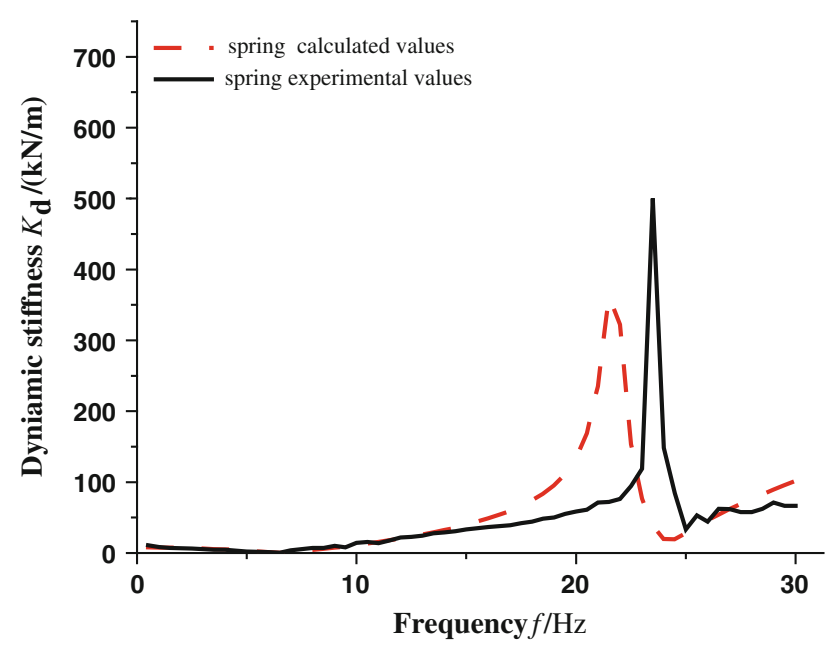

Fig. 7 Calculated and experimental values of spring dynamic stiffness

this method should be adopted in accords to the needs and objectives of the particular research case.

To obtain more accurate results, the authors have previously discussed on the need of taking into consideration the dynamic stiffness of suspension elements $[12,13]$ to talk about. Figure 7 shows the results of a spring stiffness achieved through calculation and tests based on the finite element model. When the vibration frequency is zero, the stiffness is the static stiffness of the spring itself. But with the increasing of the vibration frequency, the spring stiffness decreases, and reaches to the minimum point when the spring resonates. If the spring stiffness increases further, its stiffness becomes gradually larger, and reaches to a peak value on the antiresonance point. At this point, the stiffness is well larger than the static stiffness of the spring. Calculation results show that, with increasing vibration frequency, the resonance and opposing resonance appear to switch places, and the spring dynamic stiffness is observed to increase even though it fluctuates by a little. However, the dynamic stiffness presented in the frequency domain is hard to be used for the time domain. Therefore, the paper proposed a multi-mass-block equivalent model. When the spring static stiffness is $K_{S}$, the spring mass is $m$, if the number of the used mass block is set as $N$, the following equation is obtained:

Each spring static stiffness in the equivalent

$$
\text { model }: K_{\mathrm{N}}=N K_{\mathrm{s}}
$$

Each block mass in the equivalent model $: m_{\mathrm{N}}=\frac{m}{N}$

In Fig. 8, it is shown that the spring dynamic stiffness calculated by the multi-mass-block is basically similar with the single spring stiffness, especially when the working frequency is low. The results prove that the multi-mass-block equivalent model can be used to represent the dynamic stiffness of the spring in the time-domain calculation.

In Eq. $1,\left\{F_{o i}\right\}$ is the external force acting on a certain vehicle, which may be a superposition of the gradient resistance,

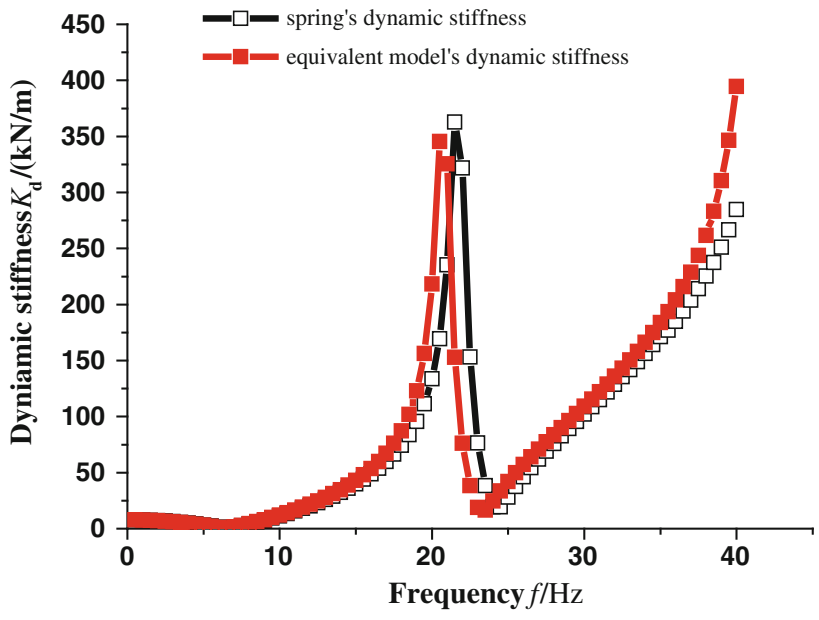

Fig. 8 Dynamic stiffness of spring and equivalent model

unbalanced centrifugal force on curve, wheel-rail force, and pantograph-catenary force (which can be ignored comparing to other forces though). If the fluid-solid coupling is considered, the aerodynamic force should also be added to the above list.

When a train is running at a high-speed, the air force it receives includes resistance, lift force and side force (or torque). In traditional VSD, generally only one vehicle under constant motion is taken as the studied object. No longitudinal motion and no air resistance are considered in the process. On the contrary, for the new VSD based on the coupled train system, longitudinal dynamics should also be considered for traction power calculation. At this point, the resistance exerted onto the train can not be neglected, and can be calculated in advance through the aero-dynamics of the vehicle and then added into the model as an external force.

According to the actual effect on the operation performance and safety of the train, the aerodynamic forces can be further divided into two types that are aerodynamic lift and side force. Aerodynamic forces can result in derailment, especially in conditions when the train is running in crosswinds. From above, the fluid-solid coupling is necessary in the calculation of the new VSD based on the coupled train system, and three different calculation methods are adopted in the related research.

Method 1: without considering the train operation attitude, the stable aero-concentrated forces (torques) are calculated by fluid dynamics software, and then implemented into the vehicles to calculate the off-line fluid-solid coupling. This method is a traditional means for calculating the train aerodynamics, and only adaptable for train aerodynamic calculations running under stable airflow, in open air, and the accuracy of this method is not very high.

Method 2: considering the train operation attitude under the action of aerodynamic forces, the fluid-solid coupling is first calculated to obtain the changes of train operation 


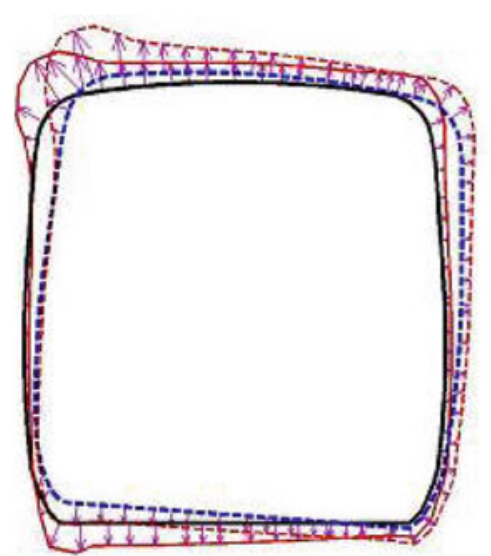

(a) Vehicle attitude change

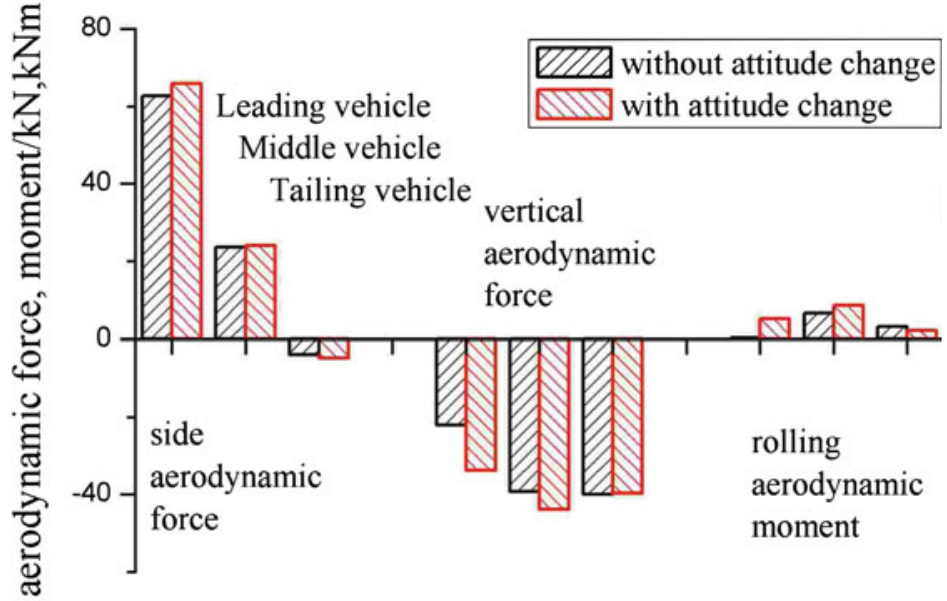

(b) Variation of aerodynamic force and moment

Fig. 9 Influence of cross-wind on vehicle attitude and aerodynamic force

attitude, under the action of stable airflow. Then the aerodynamic force under stable train operation performance is input into the train system model to calculate the off-line fluid-solid coupling parameter. In comparison to the traditional one, this method can improve the calculation accuracy [14], seen in the Fig. 9.

Method 3: the aerodynamic force is exerted onto the train coupled system dynamics model in real time, and the changes caused by any adjustments in the train operation attitude, is reflected timely for the actual fluid-solid coupling calculation. This method requires summing up all the changes the train experiences so the calculation efficiency is low. However, for the study of dynamic processes during which trains cross one another, passing by a tunnel, or being acted under fluctuating winds, this method is the sole choice.

Since the most immediate disturbance a running train experiences comes from the track, the wheel-track interaction is the most crucial and fundamental aspect in VSD study. In addition, in-depth studies require putting more attention on the vehicle-track interaction, that is, to build up a more precise coupled track model. Considering the vehicle-track interaction makes the modeling much harder, but on the other hand, improves the calculation accuracy to an extent.

In reference [15], simulations of the vehicle lateral dynamics performance under the vehicle-track interaction model and under the traditional vehicle model are given and compared. Comparisons of the ride indexes are shown in Table 2, which indicate that, in the updated model considering interaction, the elastic action of the track improves the car body's ride quality, thus simulation results considering track performance coincide better with experimental results. Reference [15] also presented studies on the calculation differences in motion stability. Taking into account the vehicle-track interaction, the elastic track was found to play a part in the vibra-
Table 2 Comparison of ride indexes of the interaction model and of traditional model

\begin{tabular}{lllll}
\hline \multicolumn{2}{l}{ Car body lateral ride index } & & \multicolumn{2}{l}{ Car body vertical rideindex } \\
\cline { 1 - 2 } \cline { 5 - 6 } $\begin{array}{l}\text { Interaction } \\
\text { model }\end{array}$ & $\begin{array}{l}\text { Traditional } \\
\text { model }\end{array}$ & & $\begin{array}{l}\text { Interaction } \\
\text { model }\end{array}$ & $\begin{array}{l}\text { Traditional } \\
\text { model }\end{array}$ \\
\hline 2.636 & 2.681 & & 2.665 & 2.674 \\
\hline
\end{tabular}

tion of the whole vehicle system, which made the vehicle prone to hunting behaviors and reduced the critical speed by several percentages. This result shows that it is necessary to take into consideration the structure of the track in order to represent the performance of vehicles in a more precise manner, and especially in high speed rail.

Timoshekno used the simple elastic beam to study the dynamic/static stress in 1927 [16], and this method is still in common use today, especially in traditional vehicle system dynamics. The track dynamics model underwent a long evolution progress, going through the lumped parameter model, then the single elastics supported continuous beam model without considering vibration of the rail infrastructure, the multiple elastics supported continuous beams model considering vibration of the rail infrastructure, the dispersed elastic ground beam model considering rail, sleeper, track bed and railway bed, and finally the finite element model [17-20].

The track dynamics and its modeling have become more adaptable and perfect after development of several decades. Figure 10 shows the multi-rigid model usually used in highspeed train dynamics systems. This model is relatively simple, but provides an accurate representation of the influence of both track structure and parameters on the train vibration due to its layered approach. 


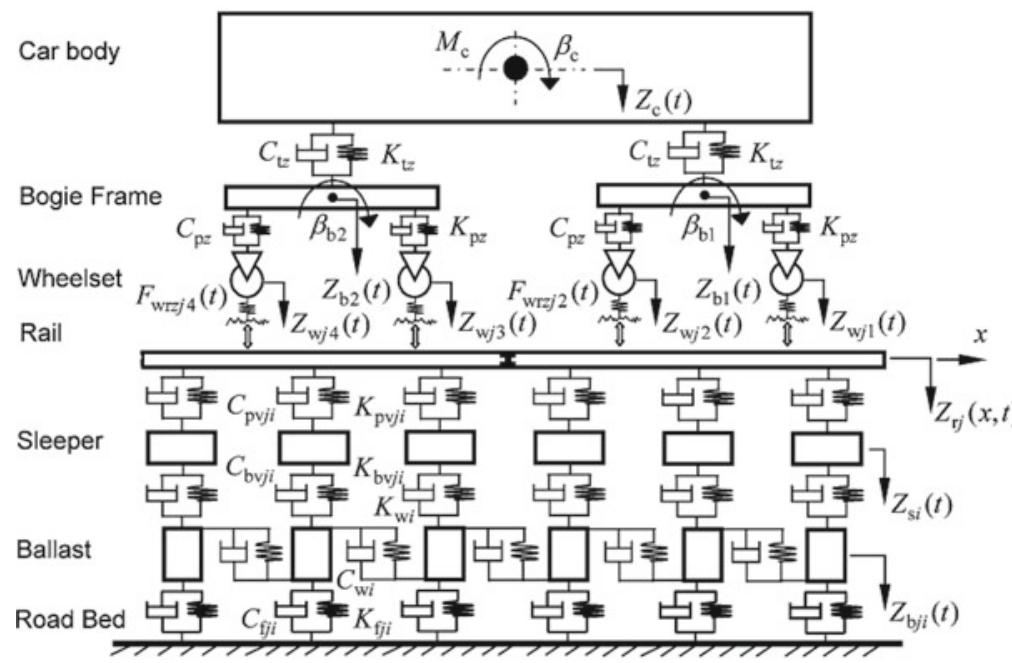

(a) Elevation

Fig. 10 Coupled vehicle/track model for ballast track

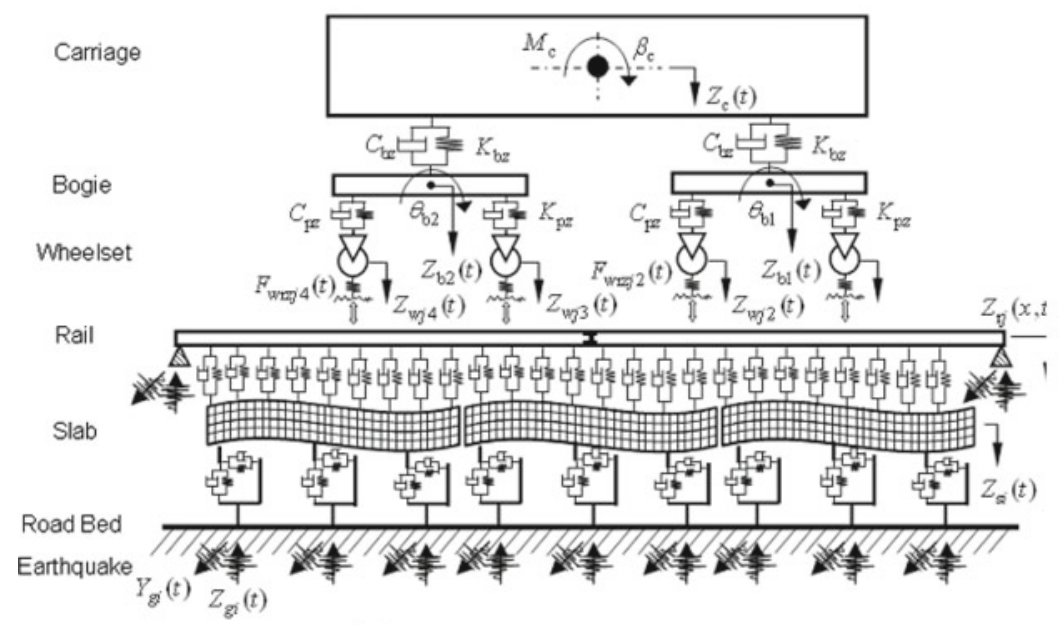

(a) Elevation

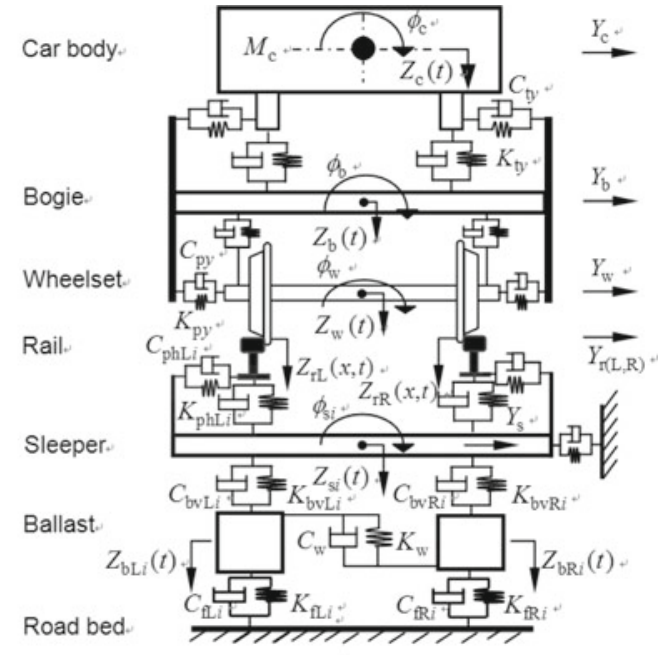

(b) Side elevation

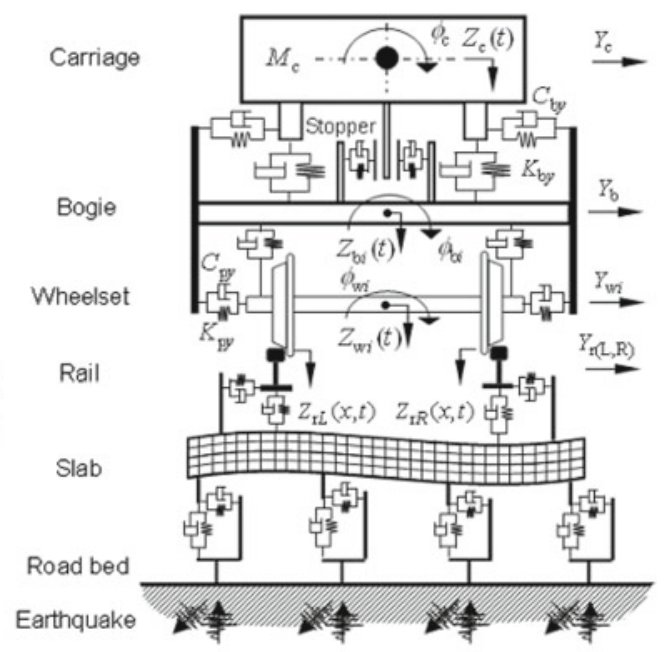

(b) Side elevation

Fig. 11 Coupled vehicle/track model for ballastless track with slab track structure

In Fig. 10b, it is seen that the classic three-layer track model, proposed by Zhai in reference [21], which considers the shear relationship of the track bed. In Fig. 11a, it is seen that in the evolving process from the original vertical vibration model to space model, the mass block on left and right in the track section is adopted, and the shear relationship is considered. Details for the model are found in reference [22].

The monolithic track bed is usually adopted in high-speed railway in China. The typical type of slab track structures consists of rails, rails fasteners, track slabs and a cement asphalt mortar (CAM) layer. The calculation model of the slab track is shown in Fig. 11 [23]. The model under consideration is composed of two Timoshenko beams for rails, 3D solid finite elements slabs, periodic discrete visco-elastic elements represented by the rail fasteners that connect the beams and the slabs, and uniformly visco-elastic elements represented by the CAM layer beneath the slabs.

In China's high-speed railways, the viaduct is commonly used and hence viaduct tracks have been developed coincidentally $[24,25]$. Due to the existence of various track forms in the long distance lines, such as ballast track, ballastless track, viaduct track and so on, the simulation of different track forms together is hard and complicated. Therefore, in simulations for practical engineering applications, the track equivalent stiffness method is used to simplify the calculation model and improve working efficiency. The results show that, this method can give a better representation of the influence in the train vibration caused by the track. 


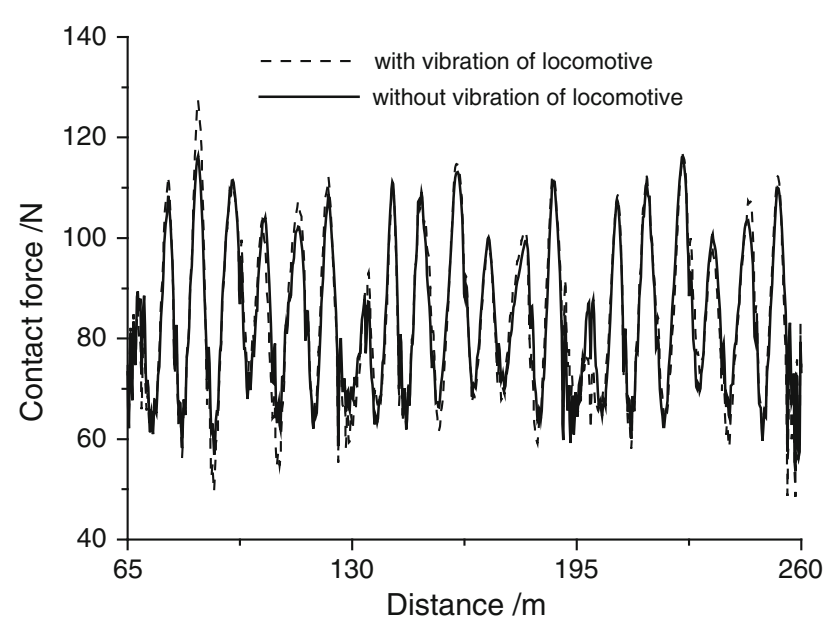

Fig. 12 Contact force of pantograph-catenary system

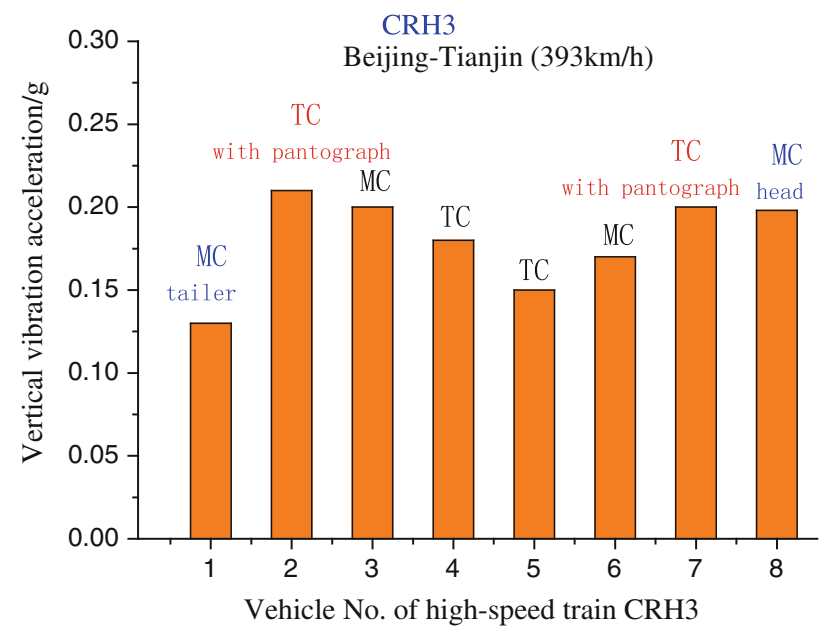

Fig. 13 Vibration acceleration of each vehicle

For the coupled system of high-speed trains, the influence of the pantograph-catenary vibration is usually ignored in the research on vehicle system dynamics, due to the fact that the dynamic forces caused by the vibration of pantograph- catenary is smaller than that of the vehicle by one order of magnitude or more. However, for the pantograph-catenary vibration, it is nevertheless affected by the vehicle vibration to some extent.

Figure 12 shows the comparisons of different contact forces while considering and ignoring the vehicle vibration [26]. It can be found that the influence of the vibration of vehicle on contact forces is around $10 \%$. Therefore, in order to accurately characterize the vibration of pantograph-catenary, we need to think about its coupled relationship with the vehicle, as well as take into account any contributions stemming from track irregularity.

Moreover, in the test run on the Beijing-Tianjin intercity rail line, it was found that, for the entire train, vehicles equipped with pantographs obtained the worse dynamics performance, as shown in Fig. 13. One of the reasons for this is that the pantograph was indeed affected by the aerodynamic force. Due to the fact that different layouts of train roofs causes different air flow patterns, the aerodynamic force of the pantograph, especially the aerodynamic uplift force and airflow disturbance were affected, and eventually affecting the quality of current collection. The abovementioned observations proves that it is necessary to include the pantographcatenary vibration into the coupled system of high-speed train.

The pantograph modeling evolved from the traditional lumped mass model to the rigid-flexible model, and then to the full flexible model [27-30], all shown in Fig. 14, where, (a) shows the multi-rigid-body model considering the pantograph frame as a rigid mechanism, (b) shows a three-massmodel, a traditional lumped mass model, considering the elastic upper frame of the pantograph, (c) is a rigid-flexible hybrid model adopted by this paper, in which the slide plates of the pantograph are taken to be as an elastic body and the pantograph frame employs the three-mass-model. (d) is obviously a perfect model which considers the pantograph head and frame both as flexible bodies. However, since the frame

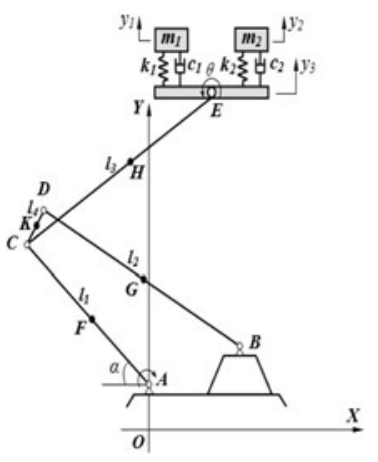

(a) Multiple rigid model

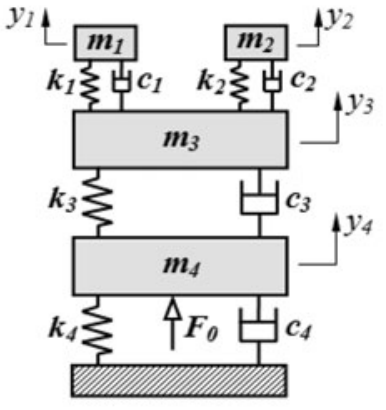

(b)Lumped mass model

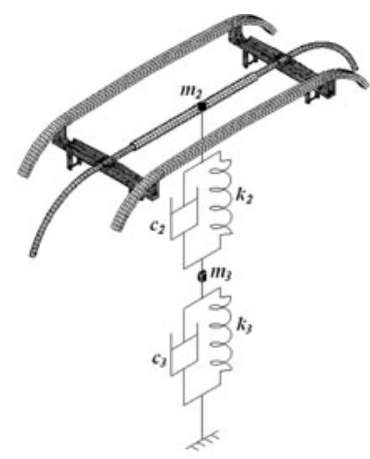

(c) Rigid-flexible hybrid model

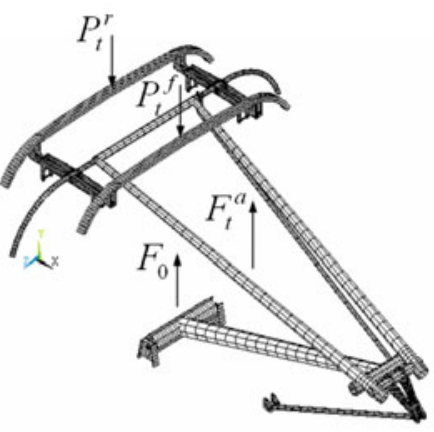

(d) Full flexible model

Fig. 14 Evolution of pantograph model 


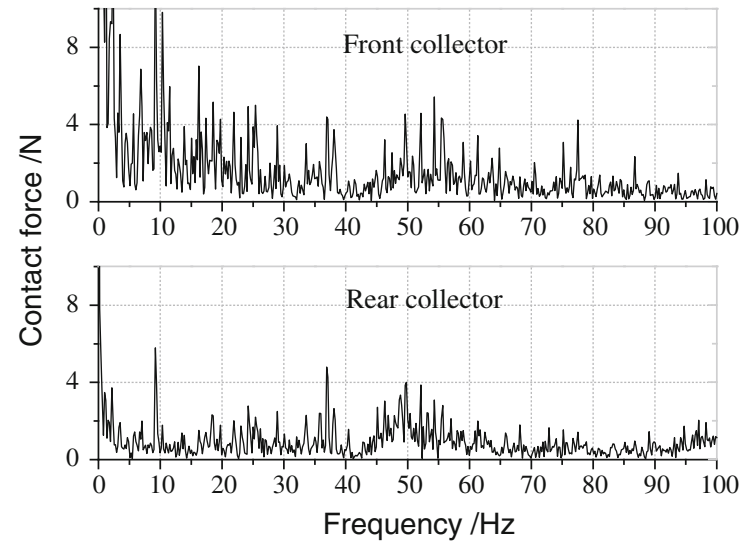

(a) Frequency spectrum of contact force of front and rear collectors

Fig. 15 Calculation results of rigid-elastic pantograph model

uses a finite element model, the calculation timescale for this method will be increased dramatically.

Figure 15 shows some numerical examples of the rigidflexible hybrid model considering the flexibility of the slide plates, also indicates comparisons between itself and the lumped mass model. It can be easily found that the vibration frequency $(48.8 \mathrm{~Hz})$ of the first-order bend modal for the slide plates is included in the contact force, as shown in Fig. 15a. It is easy to produce contact loss while considering the flexibility of the slide plates, as shown in Fig. $15 \mathrm{~b}$.

There are three major kinds of catenary models at present. The first model considers the bending stiffness and tensile stiffness of both the contact wire and support wire, as well as the elastic of the dropper. This model studies the displacements of the contact wire and support wire with Fourier decomposition, and takes the coefficients as generalized variables, using the Lagrange method to establish the motion differential equation [31-33]. The second model considers the contact wire and support wire as the beam, and deduce the partial differential equation of motion directly [34,35]. The third applies the finite method [36,37] commonly used in recent days.

While calculating the pantograph-catenary interaction, the modal superposition method is used generally to investigate the catenary, which takes the catenary vibration model as generalized variables and solve the pantograph-catenary vibration equation together by combining with the pantograph. However, with the wider application of the finite element model, more researchers adopt direct integration methods and more accurate calculation can be achieved by this means.

In the modeling of pantograph-catenary contact points, the traditional method is to adopt the equivalent contact stiffness model, in which the contact is described by point to point. In recent investigations, the authors proposed to also

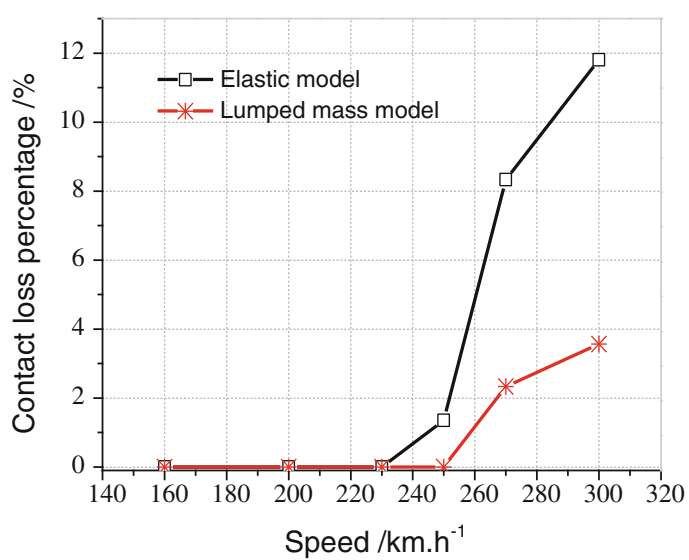

(b) Contact loss percentages of two models

take into account the geometric appearance characteristics of the contact surfaces of the pantograph and catenary. By doing this, the non-linear contact stiffness can be represented as well as the components of the catenary at various directions, making it possible and adaptable to the simulation of longitudinal contact impacts and simulation of pantographcatenary contact friction and wear.

The study of vast system dynamics obviously focuses its research on high-speed train, while considering major interactions occurring during operation, which affect the train dynamics performance, such as wheel-rail relations, pantograph-catenary interaction, and fluid-solid coupling. Based on the electromechanical interaction, the train traction power can be studied, and simulation of the traction and train operation control is carried out. The model includes the $27.5 \mathrm{kV} / \mathrm{AC} / 50 \mathrm{~Hz}$ power supply system, electric feature for pantograph-catenary contact points and traction transmission for traction transformer-converter-inverter-motorwheelset. No more details would be given in this paper regarding this model, for the electrometrical coupling is not a pure dynamics project, and more space is needed for other topics.

\section{Research of vast system dynamics of high-speed train system}

The dynamics research goes through the whole process of design, application and maintenance of the high-speed train. Its first priority is to optimize the design. Within the theoretical framework of the system, the dynamics research should consider various boundary conditions during train operation, including catenary structure and parameters, track structure and parameters, and air flow direction and speed. Indicators for the core objectives are stability, ride comfort, safety and 
Fig. 16 Vase system dynamics research for high-speed trains

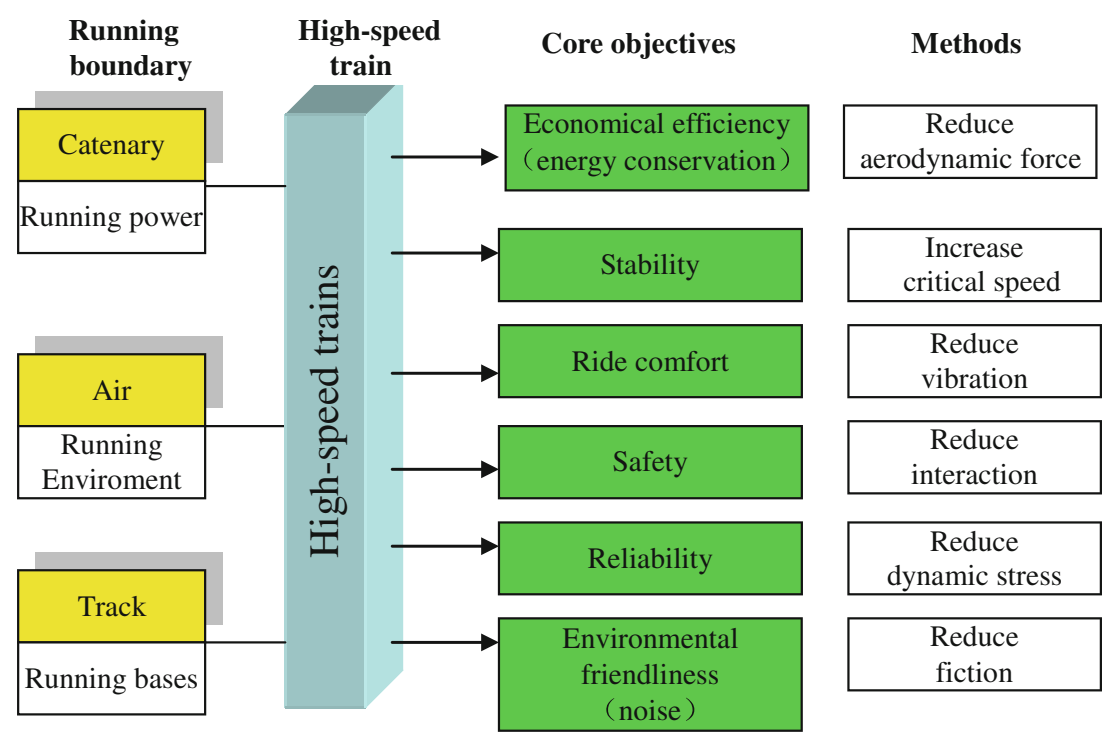

Fig. 17 Simulation for high-speed train in service
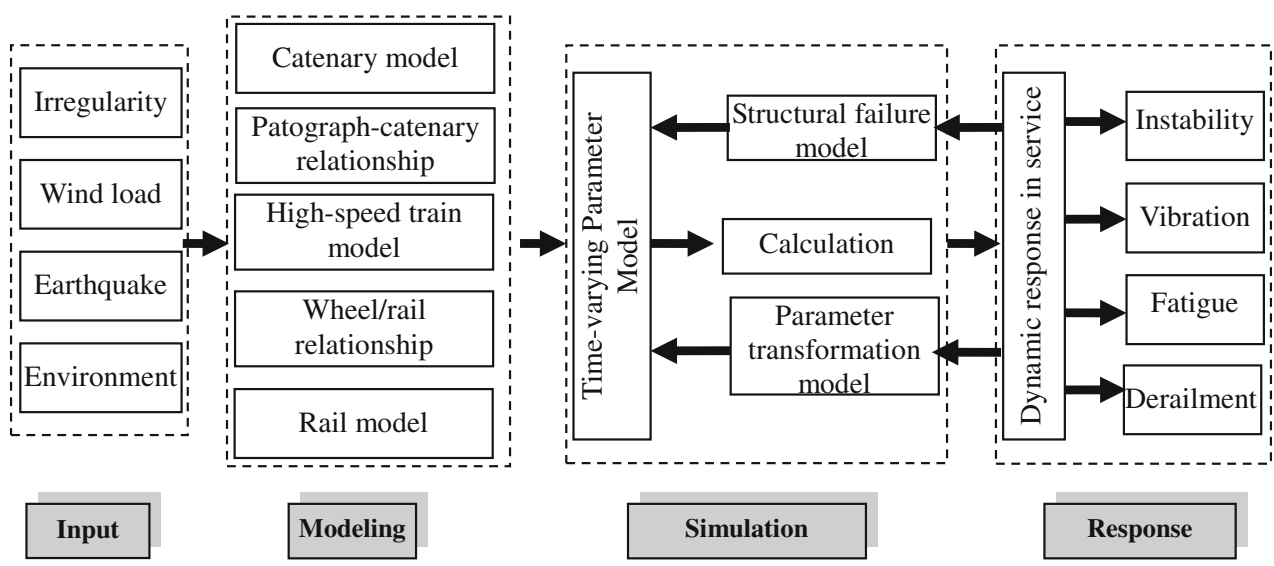

reliability, as well as economical efficiency (anti-drag and regenerative braking) and environmental friendliness (noise). In practical engineering construction, the major task is to increase the critical speed, meanwhile, reduce the vibration, aerodynamic force, and improve the interaction between the wheel and rail and between the pantograph and catenary. These objectives are what dynamics research on high speed rail needs to achieve and are summarized into a diagram as shown in Fig. 16.

The traditional vehicle system dynamics is mainly taken as an auxiliary means for computer aided design, providing advice for structure design and deciding the theoretical values for the design parameters. However, due to the continued servicing of parts, the train and its coupled track and pantograph-catenary systems will, during the long servicing process, change in terms of structural geometry parameters and even deteriorate to a certain extent as to cause accidents to occur. Hence, studies on the vast system dynamics of highspeed train can not only focus on the performance simulation, but should also focus simulating the service aspects, such as the study of how the parameters change with respect to time and how structure failures influence the train operation and response.

Figure 17 shows the calculation diagram of the service simulation, the model is a system model for the coupled system of high-speed train. For the purpose of service simulation, the time-varying parameter model is added and it quantifies a series of values that may change in time such as wheel tread wear, suspension parameter values, and even the structure failure status. Then a new simulation calculation will be carried out to achieve the system response, according to the boundary conditions set forth for the particular train in operation.

This system response will trigger in return new changes in parameters and structure status, thus a cyclic iterative technique being created between the system response and the time-varying parameter model. By this means, the dynamic behavior of the train in service will be predictable and a set of evolution rules for the service performance can be obtained. This method helps to discover deterioration in the system performance, such as instability, vibration, and fatigue, to avoid derailments and other unwanted accidents. To sum it up, the 
Fig. 18 Track irregularity power spectral density of Beijing-Tianjin intercity high-speed railway

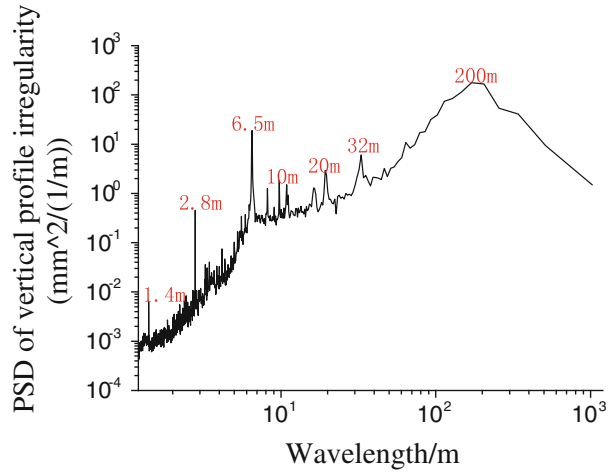

(a) Vertical Profile irregularity

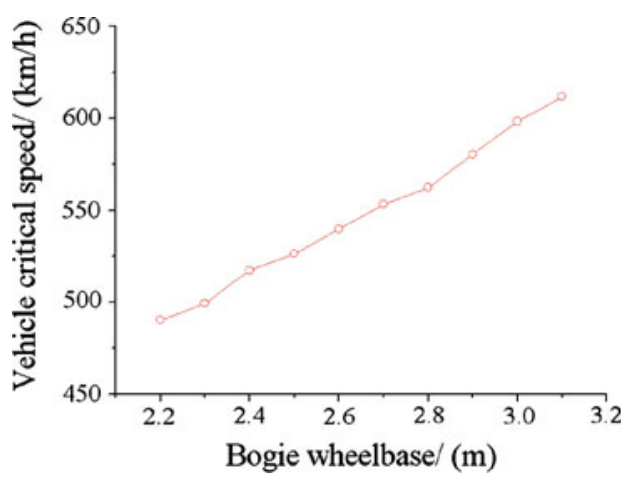

(a) Wheelbase

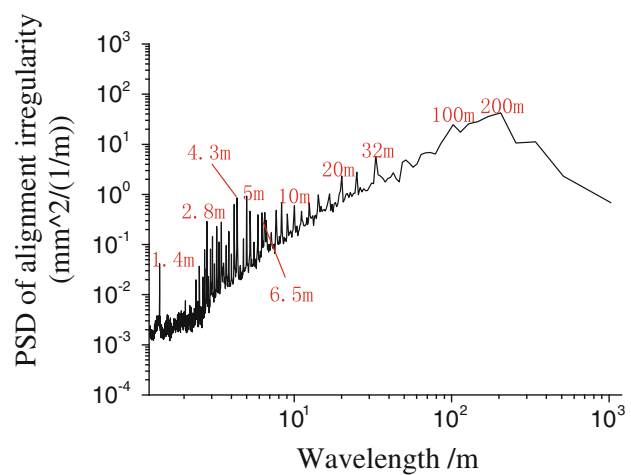

(b) Alignment irregularity

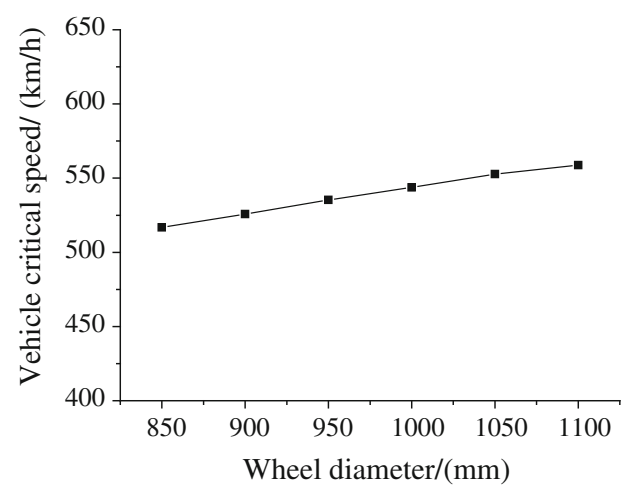

(b) Wheel diameter
Fig. 19 Influence of vehicle structure parameters on critical speed service simulation is an important research method for safety evaluation, status overhaul and maintenance, enlarging the VSD research to a higher level.

The VSD theory is now widely used in the train design, test running, operation and maintenance.

\subsection{Dynamics performance design for high-speed train}

The dynamics performance design for high-speed train focuses on the optimization design for suspension parameters. As important as in the vehicle dynamics study, motion stability, ride quality and safety are three key factors in the study of high-speed train dynamics. The optimization design is based on the train's designed speed, the boundary conditions for calculations are the track status including the horizontal and longitudinal cross sections of tracks, and the irregularity spectrum. Figure 18 shows an irregularity spectrum of a track [38], in which a large number of peaks appears and the most remarkable peak is at $6.5 \mathrm{~m}$, equal to the length of the slab of a ballastless track, and the length of the viaduct of $32 \mathrm{~m}$ is also reflected here.

In the dynamics performance design, the items that need to be optimized include, wheel tread shape, wheel base, wheel diameter, parameters of primary and secondary suspensions, etc. Figure 19 shows the effect of wheelbase and diameter of the test train on critical speeds.

\subsection{Prediction of the dynamics performance of a train in service}

The time-variance of parameters for a train in service is unavoidable, especially for the wheel profile, which exhibits a huge influence on the train's running stability. In Fig. 20, it shows four sets of data describing the wheel tread wear collected after every $50,000 \mathrm{~km}$ of a $\mathrm{CRH} 2$ train running on the exiting lines. The corresponding wheel diameters are shown in Table 3, in which the distinct concave wear appears on the wheel tread, along with wheel diameter differences. According to the measured tread status, its stability and ride comfort can be predicted by matching the worn wheel with the new rail that does not have any wear. By the results showed in Table 3, we can see that with the increasing of the wheel tread wear, the critical speed decreases dramatically and the lateral ride index drops [39].

\subsection{Safety domain for cross-wind}

Presence of cross-winds is a major influential factor for operation safety. There were many accidents in which trains were overturned by cross-winds. Like mentioned above, to study the operation safety under cross-wind based conditions on the train dynamics system, the fluid-solid coupling in Method 2 should be adopted. 
Fig. 20 Actual worn wheel profile

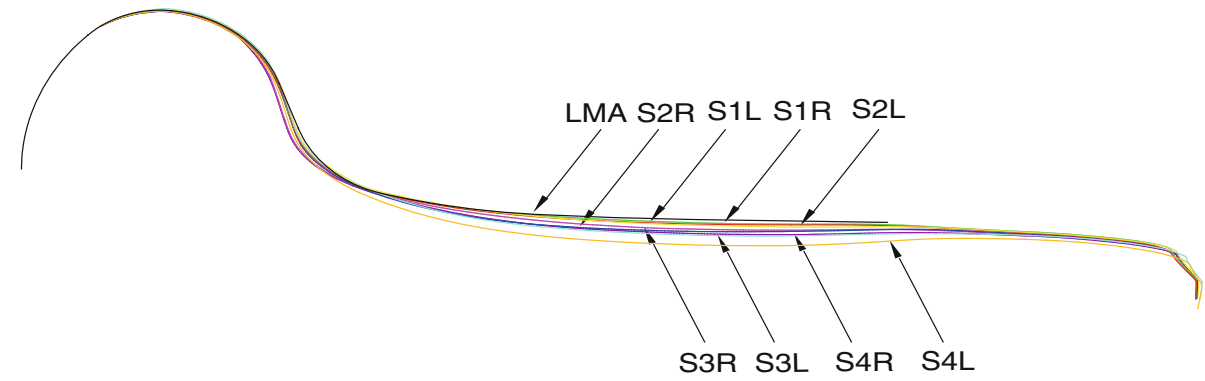

Table 3 Influence of wheel wear on vehicle critical speed and ride comfort

\begin{tabular}{lllllllll}
\hline Case no. & $\begin{array}{l}\text { Left wheel } \\
\text { profile }\end{array}$ & $\begin{array}{l}\text { Right } \\
\text { wheel } \\
\text { profile }\end{array}$ & $\begin{array}{l}\text { Leftwheel } \\
\text { diameter } \\
(\mathrm{mm})\end{array}$ & $\begin{array}{l}\text { Right } \\
\text { wheel } \\
\text { diameter } \\
(\mathrm{mm})\end{array}$ & $\begin{array}{l}\text { Wheel } \\
\text { diameter } \\
\text { difference } \\
(\mathrm{mm})\end{array}$ & $\begin{array}{l}\text { Critical } \\
\text { speed } \\
(\mathrm{km} / \mathrm{h})\end{array}$ & $\begin{array}{l}\text { Lateral } \\
\text { Sperling } \\
\text { Index }\end{array}$ \\
\hline 0 & LMA & LMA & 860.0 & 860.0 & 0 & 543 & $\begin{array}{l}\text { Vertical } \\
\text { Sperling } \\
\text { Index }\end{array}$ \\
1 & S1L & S1R & 858.99 & 859.73 & 0.74 & 480 & 2.8684 \\
2 & S2L & S2R & 858.3 & 856.71 & 1.59 & 475 & 2.7591 \\
3 & S3L & S3R & 855.73 & 857.82 & 2.09 & 472 & 2.8047 \\
4 & S4L & S4R & 853.68 & 856.68 & 3 & 344 & 3.1902 \\
\hline
\end{tabular}

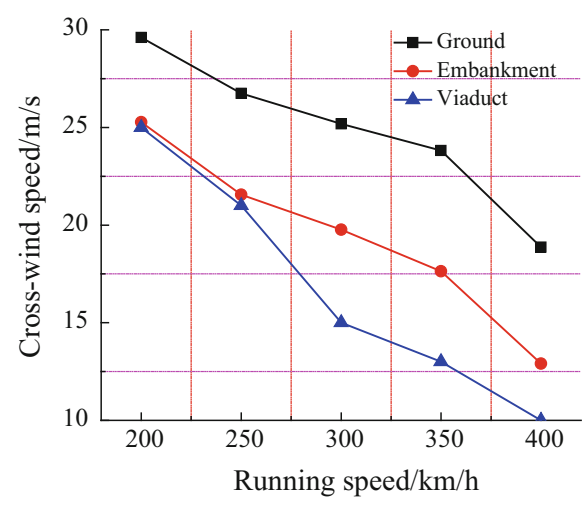

(a) Running in the open air

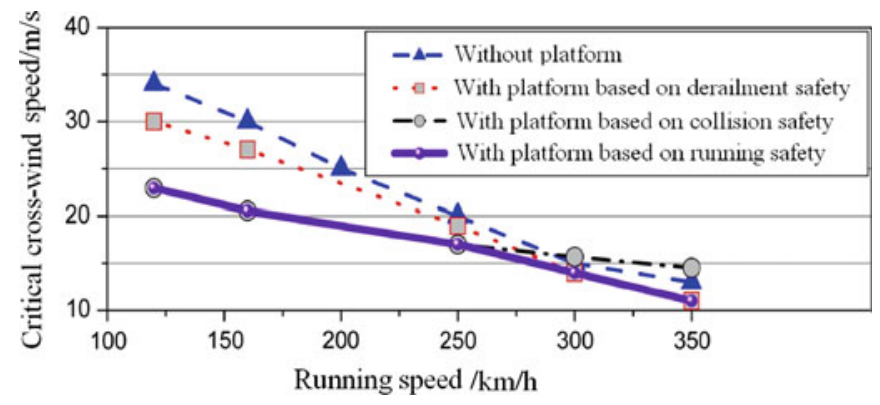

(b) Passing through a platform

Fig. 21 Safety domain of a high-speed train in cross-wind

Indexes for operation safety include derail coefficient $Q / P$, reduction ratio of wheel-load $d P / P$, wheelset lateral force $H_{\max }$, and overturning coefficient $D$. Figure 21 shows the results of an example that calculated the safety domain for cross-wind conditions [40,41], where, Fig. 21a shows the different safety domains for the studied train model running with, such as running on flat lands (ground), high embankments and viaducts. It is found the combination of crosswinds on a train running on a viaduct causes the biggest risk as the safety domain decreases with the increase of the train's running speed. Figure $21 \mathrm{~b}$ shows the safety domain for cross-winds while a train of another type is passing through a platform. The interval space from the platform to the car body was $70 \mathrm{~mm}$. Due to the influence of the cross-wind and the possible clash with the platform, the safety domain under cross-winds when the train is passing through platforms is less than the safety domain on non-platform regions.

\subsection{Track design}

There are three major factors which need to be considered and analyzed in track design. Firstly, design of cross sections, which include the curve radius, shape of transition curve, gradient and grad points. Secondly, the track stiffness design, particularly the rate of stiffness change on the track-bridge transition section. Lastly, the limit of irregularity, which includes irregularity, twist, and wave harmonics. Figure 22 shows the relationship between the twist and the 


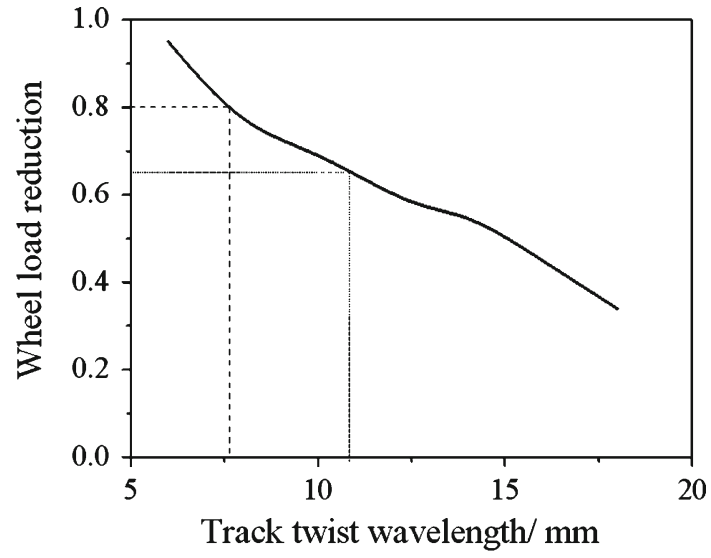

Fig. 22 Relationship between track twist

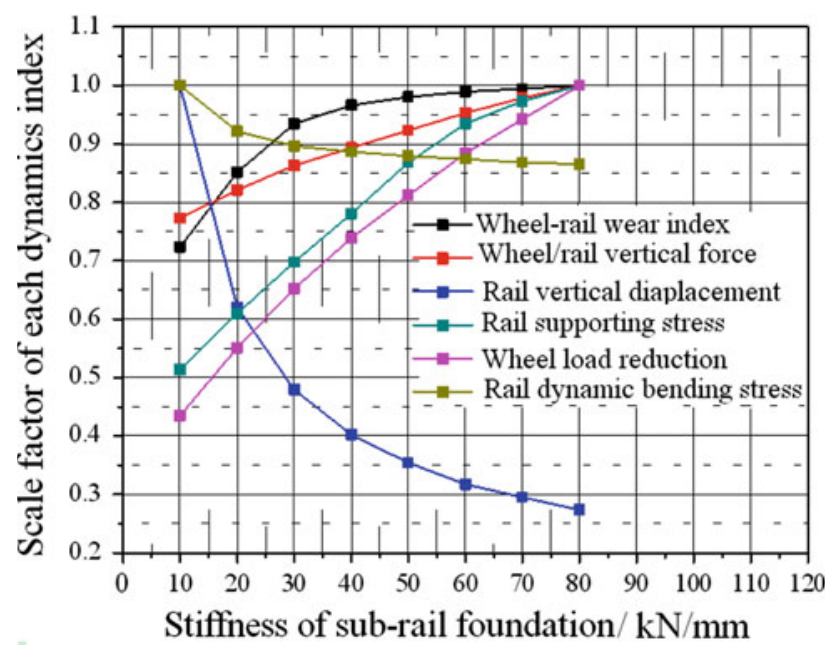

Fig. 23 Effect of stiffness of sub-rail foundation of and wheel load reduction ballastless track on wheel/rail dynamic performance

wheel load reduction. The latter is found to become larger as the wavelength in the twist decreases.

When taking into consideration the effect of shortwave on the reduction ratio of the wheel-load in random irregularity, the short wave irregularity should be controlled to within $2.5 \mathrm{~m}$ at the speed of $250 \mathrm{~km} / \mathrm{h}$, on the contrary, when the speed reaches $350 \mathrm{~km} / \mathrm{h}$, it should be within $3 \mathrm{~m}$.

Figure 23 shows the analysis of the stiffness of sub-rail foundation of ballastless track. The appropriate values should be $20-30 \mathrm{kN} / \mathrm{m}$ in light of the comprehensive influence by the track on the system performance.

\section{Conclusions}

The development and further innovation of high speed railways will always be built upon strong fundamentals and theoretical research. For this, the authors are dedicated to expanding the traditional vehicle system dynamics theory to a higher and more complete level, encompassing track, pantograph-catenary, power supply, airflow and so on.

This new method is not only meant for a more accurate representation of dynamics performance and dynamic characteristics of high-speed trains, but also for a more precise study of various relationships between wheel and rail interaction, pantograph and catenary, fluid and solid, as well as electromechanical interaction. These investigations will facilitate the design for track, pantograph, catenary, and power supply, and will ensure the safe operation of high speed trains. The newly developed VSD enlarges the traditional VSD to include a plethora of other degrees of freedom making it a vast system dynamics (also VSD), giving VSD a new meaning. Many more achievements obtained in China's railway innovation and safe operation is based on this method (vast system dynamics), and the authors envision more successes to come in the near future to be reported on other accounts.

Acknowledgments This work is supported by the National Natural Science Foundation (51075341), the National 973 Project (2011CB711105) and National Key Technology Support Program (2009BAG12A01) of China. The authors would like to thank Miss Zhang Yan and Dr. Yan Fei-xiang for their help in correcting the language.

\section{References}

1. Zhang WH, Wang BM (2010) Innovation and development of high-speed railway in China. In: Electric drive for locomotives. No. 1:8-12, 69 (in Chinese)

2. Zhang SG (2010) Study on technology system and system integration method of China high-speed railway. In: ASME conference proceedings, JRC2010-36220, Urbana, pp 501-506

3. Railway-technology.com (2012) China's high-speed rail revolution. http://www.railway-technology.com/features/feature124824/

4. Zhang WH (2006) Dynamic simulation of railway vehicles. China Railway Press, Beijing (in Chinese)

5. Zhang WH, Zhang BG (2008) Dynamics and service simulation for general coupling system of high-speed trains. J Southwest Jiaotong University 43(2):147-152 (in Chinese)

6. Zhang WH, Chi MR, Zeng J (2005) A new simulation method for the train dynamics. In: 8th international heavy haul conference, 14-16, June 2005, Rio de Janeiro-Riocentro, pp 773-778

7. Li WT, Zhang WH, Miao HT (2012) Dynamic analysis and modeling optimization of freight trains considering flexibility. Fail Anal Prev 7(3):137-142

8. Wu PB, Zeng J, Dai HY (2004) Dynamic response analysis of railway passenger car with flexible carbody model based on semiactive suspension. Veh Syst Dyn 41(Suppl):774-783

9. Dinana G, Cheli F, Bruni S, Collina A (1995) Dynamic interaction between rail vehicles and track for high-speed train. Veh Syst Dyn 24(Suppl):15-30

10. Fraczek J (2001) Modeling and dynamical analysis of flexible vehicle using FEM and MS approach. In: 16th European MDI user conference, Berchtesgaden

11. Miao BR, Xiao SN, Zhang WH et al (2007) Fatigue life simulation of flexible carbody under dynamic loading. J Southwest Jiaotong University 42(2):217-222 
12. Liu L, Zhang WH (2007a) Frequency variety analysis and equivalent algorithm of metal spring stiffness. J Traffic Transp Eng 7(5):24-27 (in Chinese)

13. Liu L, Zhang WH (2007b) Study on dynamic characteristics of metal helical spring. Sciencepap Online 2(9):674-684 (in Chinese)

14. Cui T (2011) Study on fluid-solid coupling vibration and running safety of high-speed trains. Doctor Degree Dissertation, Southwest Jiaotong University (in Chinese)

15. Wang KY, Zhai WM, Cai CB (2003) Simulation of lateral dynamic performances of locomotives and vehicles - comparison of vehicle/track coupling model with traditional vehicle model. J Southwest Jiaotong University 38(1):17-21

16. Timoshenko S (1927) Method of analysis static and dynamical stresses in rail. In: Proceedings of the 2 nd international congress for applied mechanics, Zürich

17. Cai Z, Raymond GP (1994) Modelling the dynamic response of railway track to wheel/rail impact loading. Struct Eng Mech 2(1):95-112

18. Knothe K, Grassie SL (1993) Modeling of railway track and vehicle/track interaction at high frequencies. Veh Syst Dyn 22(3-4):209-262

19. Sun YQ, Dhanasekar M (2002) A dynamic model for the vertical interaction of the rail track and wagon system. Int J Solids Struct 39(5):1337-1359

20. Jin XS, Wen ZF, Wang KY et al (2006) Three-dimensional train/track model for study of rail corrugation. J Sound Vib 293(3-5):830-855

21. Zhai WM, Sun X (1994) A detailed model for investigating vertical interact ion between railway vehicle and track. Veh Syst Dyn 23(Suppl 1):603-615

22. Xiao XB, Jin XS, Wen ZF et al (2011) Effect of tangent track buckle on vehicle derailment. Multi-Body Dyn 25(1):1-41

23. Xiao XB, Jin XS, Wen ZF et al (2009) Effect of earthquake on highspeed railway vehicle running safety. In: 21 st international symposium on dynamics of vehicles on roads and tracks (IAVSD'09), 16-20 Aug 2009. KTH, Stockholm

24. Zhai WM (2007) Vehicle-track coupling dynamics. Science Press, Beijing (in Chinese)

25. Zhai WM, Xia H (2011) Train-track-bridge dynamic interaction: theory and engineering application. Science Press, Beijing (in Chinese)

26. Zhang WH (1997) On dynamic behavior of the quasi-highspeed catenary. J Southwest Jiaotong University 32(2):187-192 (in Chinese)

27. Zhang WH, Shen ZY (1993) A dynamic analysis of the pantograph. J China Railw Soc 15(1):23-30 (in Chinese)
28. Wormley DN, Seering WP, Eppinger SD et al (1984) Dynamic performance characteristics of new configuration pantographcatenary Systems. Final Report, Department of Mechanical Engineering, Massachusetts Institute of Technology, Cambridge. DOT/OST/P34/85/023/Oct. 1984

29. Park TJ, Han CS, Jang JH (2003) Dynamic sensitivity analysis for the pantograph of a high-speed rail vehicle. J Sound Vib 266(2):235-260

30. Zhou N, Zhang WH (2009) Investigation of the influence of panhead elasticity on pantograph-catenary dynamic performance. In: 21 st international symposium on dynamics of vehicles on roads and tracks (IAVSD'09), 17-21 Aug 2009, Stockholm

31. Eppinger SD, O'Connor DN, Seering WP et al (1998) Modeling and experimental evaluation of asymmetric pantograph dynamics. ASME J Dyn Syst Meas Controls 110(2):168-174

32. Zhang WH, Mei GM, Zeng J (2002) A study of pantograph/catenary system dynamics with influence of presag and irregularity of contact wire. Veh Syst Dyn 37(Suppl):593-604

33. Zhang WH, Mei GM, Wu XJ et al (2002) Hybrid simulation of dynamics for the pantograph-catenary system. Veh Syst Dyn 38(6):393-414

34. Zhai WM, Cai CB (1997) Analysis on dynamic performances of catenary of high-speed railways. J Southwest Jiaotong University 32(5):497-501 (in Chinese)

35. Zhai WM, Cai CB (1998) Effect of locomotive vibrations on pantograph-catenary system dynamics. Veh Syst Dyn 28(Suppl 1): $47-58$

36. Zhou N, Zhang WH (2011) Investigation on dynamic performance and parameter optimization design of pantograph and catenary system. Finite Element Anal Des 47(3):288-295

37. Zhou N, Zhang WH, Li RP (2011) Dynamic performance of a pantograph-catenary system with the consideration of the appearance characteristics of contact surfaces. J Zhejiang University Sci A 12(12):913-920

38. Zhang SG (2008) Study on high-speed train design method. China Railway Press, Beijing (in Chinese)

39. Li Y, Zhang WH, Chi MR et al (2011) Influence of wheel tread profile and rolling diameter difference on dynamic performance of vehicles. J China Railw Soc 31(1):104-108 (in Chinese)

40. Yu MG, Zhang JY, Zhang WH (2011) Wind-induced security of high-speed trains on the ground. J Southwest Jiaotong University 46(6):989-995 (in Chinese)

41. Cui T, Zhang WH, Zhang BG et al (2010) Study on the fluid-solid coupling vibration of train passing through platform at high-speed. China Railw Sci 31(2):50-55 (in Chinese) 